\title{
Nurse's social responsibility: A hybrid concept analysis in Iran
}

\author{
Zahra Hadian Jazi ${ }^{1}$, Hamid Peyrovi*2, Armin Zareian ${ }^{3}$ \\ Received: 12 Sep 2018 \\ Published: 21 May 2019
}

\begin{abstract}
Background: Social responsibility in nursing is a complex concept that is completely associated with the context and healthcare system of every society. This study was conducted to analyze the concept of nurse's social responsibility in Iran.

Methods: This analysis was done using a hybrid model, which consists of three phases: a literature review in the theoretical phase, semi-structured interviews in the fieldwork phase, and combination of the results of the two previous phases in a final analytical phase.

Results: The four main themes extracted in the theoretical phase included: "Multi-dimensional and comprehensive approach", spirituality-based, learner-based and an evolutionary-process. In the fieldwork phase, all the themes obtained in the previous phase were confirmed, and one more theme emerged as "being relative". In the final phase, with the combination of the results of two previous phases, the final definition of the concept was presented.

Conclusion: Clarifying the social responsibility of nurses and highlighting it in nursing will definitely lead to satisfaction in patients and clients, professional development and reduction of health care costs. Also, by identifying facilitators, inhibitors and social responsibility concepts, nursing managers and nursing educators will be able to design and implement their management and training activities based on scientific findings based on the findings that are necessary for the correct learning and implementation.
\end{abstract}

Keywords: Social responsibility, Nursing, Hybrid, Concept analysis

Conflicts of Interest: None declared

Funding: Iran University of Medical Sciences

*This work has been published under CC BY-NC-SA 1.0 license.

Copyright $\odot$ Iran University of Medical Sciences

Cite this article as: Hadian Jazi Z, Peyrovi H, Zareian A. Nurse's social responsibility: A hybrid concept analysis in Iran. Med J Islam Repub Iran. 2019 (21 May);33:44. https://doi.org/10.47176/mjiri.33.44

\section{Introduction}

Generally, social responsibility is a form of public support for the needs of others that restates social issues; these are affected by contemporary worldwide societies and communities. As a science that focuses on human caring, nursing has both the power and knowledge to advance communities. As a professional job, nursing is also able to concentrate on the well-being of a society in advocating for social change. Due to the fact that nurses are truly the largest number of health care providers, the profession of nursing has to claim leadership in social respon-

Corresponding author: Dr Hamid Peyrovi, peyrovi.h@iums.ac.ir

1. Department of Medical-Surgical Nursing, School of nursing and midwifery, Iran University of Medical Sciences, Tehran, Iran

2. Nursing Care Research Center, School of Nursing and Midwifery, Iran University of Medical Sciences, Tehran, Iran

3. Public Health Nursing Department, Nursing Faculty, Aja University of Medical Science, Tehran, Iran sibility. Nursing has the capacity to do this, not just because it is right, but also because many nursing education courses equip nurses to assume this responsibility. Nursing has a commitment and responsibility to satisfy a social contract for care with society $(1,2)$.

Nurses are the first health care providers that link patients to other members of the health care team. Providing good-quality care and services is considered as a priority in any health care system, especially in the field of nursing care. This issue becomes more important when consider-

\section{$\uparrow$ What is "already known" in this topic:}

Nowadays, any individual who cares for social responsibility in his/her profession or career is more successful than others and can attract more clients or customers than the rest. But in nursing, this concept is not clearly defined and its dimensions not specified precisely.

\section{$\rightarrow$ What this article adds:}

The aim of this study is to analyze this concept from the Iranian nurse's perspective regarding the context of Iran, so a nurse will pay more attention to this concept in order to achieve an ideal society and can get more patients' satisfaction. 
ing that the accreditation of hospitals is drastically under the influence of nursing care quality (3). Nowadays, the level of accountability and responsibility (especially social responsibility) of staff (such as nurses in hospitals) is one of the crucial indicators of hospitals' superiority towards the counter ones (4). In order to provide the best possible quality of nursing care and patients' satisfaction, it is necessary to consider nursing performance standards which includes social responsibility (5).

Social responsibility is considered as one of the most important skills needed by humans. Creating a bright future without bringing up responsible people is not possible. The sense of responsibility allows a person to be active at the same time, to succeed, to control his inner and outer environment, to be self-regulating, and to be wise and at the same time to feel belonging to others emotionally. For these characteristics, social responsibility in nurses are very important because of their professional sensitivity (6). In fact, the importance and the role of the social responsibility of nurses in the field of health care are undeniable. Nurses are responsible for making ongoing efforts to provide safe, desirable, and high-quality care (7) and provide the patients with the nursing care without any discrimination and pre-judgment. Despite the importance of the issue of social responsibility, hospitals should pay more attention to it. This lack of adequate attention is more noticeable in some facets (such as work settings and the environment). It seems that while hospitals can react more effectively to the requirements of work and social work environments, they could improve their social responsibility provided that they offer their services while respecting the dimensions of leadership, the staff, work settings and society (8).

Florence Nightingale, Lilan Wald, and Lavinia Locke, as the pioneers of modern nursing, are also the founders of social responsibility thinking in nursing (9). According to Nightingale's environmental theory, the viewpoint of social responsibility developed and became a basis for expanding the role of nurses in improving the environment, work settings (hospital) and other similar situations (10). Spitzer (11) also highlights the importance of social responsibility in nursing contending that nurses should accept to be more sensitive toward social responsibility during delivery of care to patients and in fact social responsibility is like DNA for their job and the commitment of the nurses as professionals to their community. He also believes that providing community-based emergency services and social responsibility are issues that are at the core of the nursing mission, and they are required to establish these two measures for people in their community.

Although the concept of social responsibility has been applied in a wide range of organizations, jobs, and professions, it still remains a complex concept in nursing without any definite definition. Along with the concept of social responsibility in nursing, there are other concepts such as human rights, social justice, social participation, pluralism, freedom of expression and equality, which have made the term of social responsibility largely imprecise in the nursing (9). Kelly (2) believes that this concept is not well-defined in nursing, and one reason for this lack of an imprecise definition is that, unlike medical domain that has organizations and organs for social responsibility, nursing lacks such organizations. Furthermore, the multidisciplinary nature of nursing and its close relationship with medicine are other reasons for this concept to be largely forgiven in nursing. Indeed, a critical review of the broad studies conducted to clarify the concept of social responsibility in the nursing profession highlights two points: one is that this concept is one of the key concepts in a wide range of disciplines; and second, there is a particular view towards this concept in every discipline (12); but not enough attention has been paid precisely to this concept in nursing. In addition, the social responsibility is also influenced by social and cultural factors; and elements such as the socio-economic status, ethnicity, religion, and the extent of using mass media are effective in the emergence of social responsibility (13). Therefore, this concept depends on social, economic, cultural, religious, and even environmental factors within every community.

Nowadays, given the increase of people awareness and their familiarity with the patient rights and being more informed of cases of misconduct and negligence of the staff of health care settings, and also because of broadcasting these health faults by the media which, in turn, have caused people to be more vigilant about the type and way of care providing by health care staff, the clarification of the concept of social responsibility in nursing can lead to more effective responsibility by the nurses, and no room is left for patients to complain. Additionally, this helps nurses to be able to effectively and legally deal with the professional problems which, in turn, foster their confidence and job satisfaction and also increase the quality of their service to patients (14). All taken together, this concept is widespread, and different people in different disciplines have their own understanding of it, it is necessary to consider this concept from the viewpoint of nurses and patients.

Regarding the effect of contextual transformations on the change and development of some phenomena in each context, the researchers ought to examine the nurse's social responsibility concept and empirically, investigate its aspects in the context of hospitals in Iran. In recent decades, a lot of research studies have been conducted to clarify the concept of social responsibility and its measurement, especially in business and education sectors. However, in the nursing field, no qualitative study has ever been conducted to examine this concept from the nurses' or patients' point of view or its analysis and clarification in Iran. Also, there is no agreement on analysis, and also there is no integration of this concept from other similar concepts in this field. Analysis and clarification of this concept will help in the development of valid tools and questionnaires for the nurses, as well. The aim of this study is to examine a deep perception of the social responsibility in the nursing context in Iran.

\section{Methods}

In order to analyze the concept of nurse's social responsibility, the researchers used the hybrid model of concept analysis introduced by Schwartz-Barcott and Kim. This 
model consists of three stages of theoretical, field work and analytical phases (15). The goal of the hybrid method is concept development which is executed through qualitative examinations of a phenomenon in its place of occurrence. In this method, a specific approach is chosen, in which the theoretical and experimental methods are mixed together, and the final development of the concept is achieved inductively and by comparison in such a way that, a type of reduction was formed at the end (16).

\section{Theoretical phase}

In this phase, a literature review was done by searching international and Iranian databases like "PubMed (MEDLINE)", "ProQuest Dissertations \& Theses", "Google Scholar", Wiley", "Elsevier, Ovid, "SID", "IRANMEDEX", "MEDLIB", "Magiran" and "IRANDOC". The search keywords were "responsibility", "social responsibility", "nursing social responsibility", and some helping words like "care" and "hospital". All the articles published from 1950 to 2018 were considered. Some of the questions that had to be considered in the literature review included "What is the definition of social responsibility in nursing or care settings? How is social responsibility in nursing measured? What is the influencing factors on nursing social responsibility?" Noticing the inclusion criteria (studies in Persian or English language with related keywords in the title, abstract, or list of keywords) and exclusion criteria (unrelated issues such as social responsibility in the business or/and education and can't access the full form of article), in addition to assessing the quality of resource, in total, 41 resources (33 Persian articles, 8 English articles) were analyzed for the theoretical phase of concept analysis (Fig. 1). Data analysis was conducted using conventional content analysis. In this study, the text of each literature was carefully studied from different aspects. For example, any sentence, word or phrase implied the definition and dimensions of nursing social responsibility were identified and categorized in different categories.

Fieldwork phase: The researchers helped the theoretical phase for leading the interviews at the fieldwork phase. The research population in this phase included nurses with different responsibilities (clinical nurses in different wards, head nurses, and supervisors). Nurses are involved in the wide range of responsibilities such as caring patients, communicating with co-workers, or with their supervisors, and they have specific experiences and views about the nurse's social responsibility. Purposeful sampling approach was done for choosing the participants, and an attempt was tried to use principles of maximum variation sampling. The first author began all the interviews using open-ended questions and semi-structured interviews. The questions used in semi-structured interviews were conducted by reviewing the first phase and more questions were derived from the participants' answers. For example, some questions were: In your idea, what does social responsibility mean in nursing? Do you consider yourself as a social responsibility nurse? What features do you consider to be a social responsibility nurse? Which colleagues do you consider as a social responsibility person? What qualities do they have? After getting confirmation from the ethics committee, sampling from the targeted group got started. The inclusion criteria were: having at least a bachelor's degree in nursing, having at least 6 months of practical nursing experience in wards of hospitals, and willing to take part in the study. A total of 18 participants were recruited in the study. The interviews were done face to face and took about 30 to 60

Result from derived search on "PubMed (MEDLINE)",

Elsevier, "ProQuest Dissertations \& Theses", “,

"Wiley", Ovid, , "SID”, "Google Scholar", ,

"MEDLIB", "IRANDOC", , "Magiran"

and"IRANMEDEX" (N=1051: 970 in English \& 81 in Persian)

Duplicate records

excluded ( $\mathrm{N}=36)$

Pens

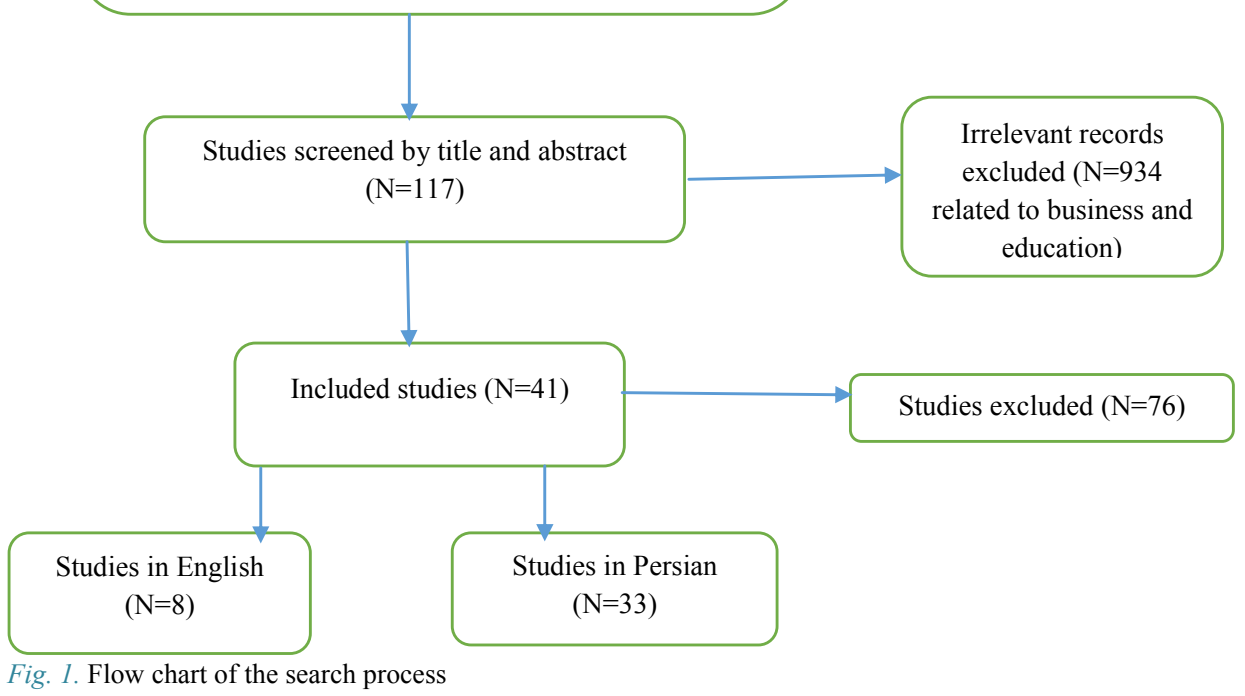


minutes. The place of the interviews was chosen based on the participants' preference. After obtaining written informed consent, the participants entered the interview. All of the interviews were recorded and then transcribed by the first author. Then, their texts were given back to the participants, and they all confirmed of whatever they had said and was accordingly transcribed by the researcher. All the gathered data from the interviews were analyzed using the qualitative approach and content analysis as described by Graneheim and Lundman. We used conventional content analysis because coding categories were derived directly and inductively from the raw data. And there weren't enough theories or documents and studies with nurse's social responsibility, especially in Iran.

After transcribing the interviews, they were coded. At first, more than 300 primary codes were extracted. Then duplicated codes were omitted and the remaining codes categorized in different categories according to their similarities, differences, and repetition through reductive classification. In order to be sure about the reliability of coding, the first author manually classified the data, and then they were reviewed and revised by the second and third author. Then the researchers compared all the categories and themes which were emerged from the interview data with those ones created through literature review, and the differences and similarities between the emerged categories and themes and those achieved through literature review were jotted down.

Scientific rigor of fieldwork data: We used more than one method for data gathering (like field note and interview) to ensure the validity and scientific accuracy of the data. Maximum variation sampling (selecting participant from nurses, medical doctors and patients in order to maximum diversity) was also applied. Prolonged struggling with the data collection and then analyzing, reviewing and modifying the codes for several times, member checking which means rechecking the meanings and codes with the participants and finally peer checking which means rechecking the meanings and codes with research team were other strategies which were used to maximize the rigor of the data.

Final analytical phase: In this phase, the codes and categories achieved from the fieldwork phase were compared with the data gathered from the literature review in the theoretical phase and then, the common features and aspects of nursing social responsibility concept were identified and the working definition of the concept was presented.

\section{Results}

Results of the theoretical phase: Fleming defines social responsibility as a set of tasks and commitments that organizations or individuals must take to preserve, care and help the community in which they work (17). Steiner and Steiner also argue that social responsibility means that organizations and individuals are accountable for actions that may affect society and the environment (18). In a simple and comprehensive definition, social responsibility can be understood as measures that ultimately help to improve the social status of the community (19). Social responsibility is considered as voluntary basis, employee empowerment, safety, and health of employees and the workplace, customer or client rights, environmental considerations, managing for energy efficiency and saving, respecting for human rights principles, codes ethics, social activities, and benevolence and philanthropic behaviors (20). Table 1 illustrates some examples of the definition of social responsibility in the theoretical phase.

According to the literature, 4 main themes of nursing social responsibility include (Table 2).

Theme One. Multi-dimensional and comprehensive approach: According to the studies that were analyzed and interpreted at the theoretical phase, social responsibility is considered as a comprehensive feature that addresses issues such as: community expectations, and also business, legal, ethical and social expectations, respect for human rights and observance the principles of human rights, fair treatment with the workforce, customers and suppliers, being good citizens for the communities in which they operate and environmental protection, employee empowerment, safety and health of employees and the workplace, customer rights, energy management and savings, ethical codes, social activities, and organizational benevolence.

Theme two. Spirituality based: An overview of studies has shown that one of the dimensions of social responsibility is paying attention to spirituality in performing du-

Table 1. Examples of the definition of social responsibility in the theoretical phase

\begin{tabular}{|c|c|}
\hline Literature & Definition of social responsibility \\
\hline Fry S (1983) & $\begin{array}{l}\text { The social responsibility of nursing linking nursing responsibility with social } \\
\text { responsibility. Fry noted that nursing has an "overwhelming social responsibility } \\
\text { of improving the health of the public" }\end{array}$ \\
\hline Tyer-Viola L, Nicholas PK, Corless IB, et al ( 2009) & $\begin{array}{l}\text { In a general sense, social responsibility is advocacy for the needs of others and } \\
\text { program implementation that reflects a focus on social issues affecting contempo- } \\
\text { rary global societies and communities }\end{array}$ \\
\hline Kelley MA, Connor A, Kun KE, Salmon ME (2008) & $\begin{array}{l}\text { Social responsibility as "closely connected with many professions, providing an } \\
\text { important construct for guiding the overall development of these professions and } \\
\text { their members" Furthermore, they view social responsibility as closely related to } \\
\text { a number of humanistic constructs, including human rights, social justice, and } \\
\text { community engagement. }\end{array}$ \\
\hline Pitzer College (2009) & $\begin{array}{l}\text { Pitzer College defines social responsibility as a core value that includes "aware- } \\
\text { ness, knowledge, and behavior based upon a commitment to the values of equity, } \\
\text { access, and justice; a dedication to civic involvement and environmental sustaina- } \\
\text { bility; and a respect for diversity, pluralism, and freedom of expression." }\end{array}$ \\
\hline American Nurses Association [ANA], 2003 & $\begin{array}{l}\text { The profession's social responsibility, is key to our profession's link to the needs } \\
\text { of society. The statement is broad encompassing the individual and society. }\end{array}$ \\
\hline
\end{tabular}


Table 2. Attributes extracted from the theoretical phase

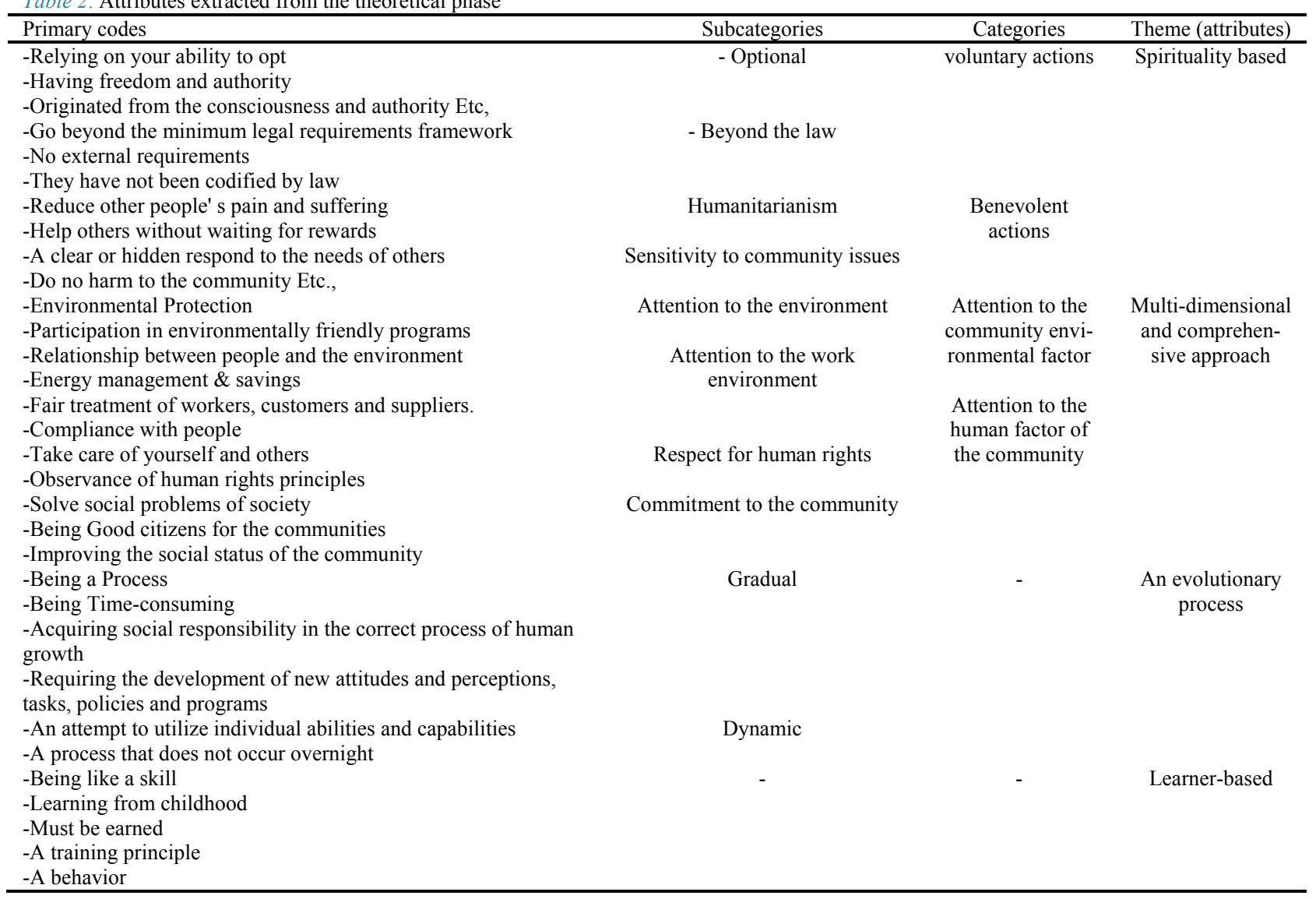

ties. The sub-categories that led to the formation of this theme were: benevolent and voluntary actions. Taghizadeh (2011) divides the organization's social responsibility into four subsystems of economic, legal, ethical, and voluntary benevolent philanthropy responsibilities, stating that ethical, benevolent, and religious-related dimensions of social responsibility have become more prominent today, believing that these are behaviors that the society expects from organizations, but not incorporated in the law (21). It's believed that someone with social responsibility is a person who is always ready to help others even when no benefits are anticipated. Also, social responsibility is considered as a behavior that is not affected by predictable rewards, and in the other hand, doing work without waiting for rewards or benefits is the same act of social responsibility (22).

Theme three. Learner-based: Social responsibility is considered as a kind of attitude and skill, which is like any other attitude and skill acquired and learned (23). Yazdan Panah and Hekmat (2014) also state that social responsibility is a process that one must learn from the earliest years of childhood to deal responsibly with the many tasks he faces in life (24).

Theme four. An evolutionary process: From the reviewed studies, it is understood that there is no sudden and immediate development of social responsibility, but rather a process that begins with responsibility, and proceeds to evolution and growth in the next and with the passage of time. Yazdan Panah and Hekmat (2014) point directly to the process of social responsibility and that it begins to be learned from childhood (24). Ahmadi et al. (2011) state that the evolution of social organizational participation begins from social commitment and ultimately ends in the social responsibility of the organization. In their article, they consider the achievement of social responsibility as a time-consuming process, and that, obviously, no organization overnight is mature enough to deal with social problems and problems in social accountability, and this is a process that is time-consuming, requiring the development of new attitudes and perceptions, tasks, policies and programs (25).

\section{Antecedents}

Antecedents of a concept are factors that should occur before the occurrence of the concept (25). After the review of the texts carried out at the theoretical phase, the antecedents of social responsibility turned out to be: responsibility (commitment to professional ethics, being law-based, acting based on professional standards), nurturing (education in the educational settings and raising by the family), factors related to individuals (thinking skills, independence, self-directedness, trustworthiness), factors related to society (media, general education, cultural investment) and factors related to the organization (collaboration and work atmosphere and rules). 


\section{Consequences}

According to the analysis of the texts in the theoretical phase, the consequences of the concept of social responsibility were classified into four categories. Social responsibility can have individual outcomes (increased selfesteem, job satisfaction, and social affiliation), impact on the organization (or hospital) (sustainability in the organization, justice), impact on society (poverty eradication and environmental protection) and, ultimately, increased quality of care and health.

Based on the literature, an operational definition of nurse's social responsibility is:

"Social responsibility is a "learner-based" attribute that is "comprehensive and spirituality-based"; it means that socially responsible people are responsible for the "environmental and human factor" of the community in which they live. They realize this responsibility through benevolent and voluntary activities without any expectations to receive rewards in return. The first step in acquiring social responsibility is that the person must be accountable, and then being sensitive to society and environment, learned later and over time in the presence of factors such as learning in the family and school, the community or the society. And it takes an evolutionary process. And ultimately, it increases job satisfaction as much as possible, creates more loyal forces in the organization, develops social justice and increases the quality of health care".

Results of the fieldwork phase: At the fieldwork phase, while approving all the themes and categories that obtained at the theoretical phase, the category of "relativity" also emerged, and it can be said that the vast majority of participants referred to it. In addition, at this phase, some subcategories were added to previous themes which had achieved in the theoretical phase.

For "Multi-dimensional and comprehensive approach "theme, subcategories such as "inter-professional communication", "multidimensionality", "considering the organization (hospital) benefits" and "having a mother-like behavior" were also added.

For the theme of "Spirituality-based", subcategories like "Attention to conscience" and "self-sacrifice" were also added. But for both "an evolutionary process" and "learner-based" themes, the results were the same, and no new results were added.

Relativity: Relativity was one of the attributes not mentioned at the theoretical phase or at least in studies that analyzed by researchers; but at the field-work phase, it can be said that all of the participants referred to it.

"We (nurses) know the basics of nursing work. But given the conditions and possibilities, for example crowded ward or lack of facilities, we need to be able to manage the situation to maximize our effectiveness ..."

Another nurse said: "On the other hand, social responsibility in medicine or nursing in our society (Iran) is a relative concept! For instance, whenever we are not so exhausted, or there is no lack of facilities or equipment ,we all do everything for our patients or clients, and consider more dimensions of social responsibility in our profession but sometimes you see, we have too many patients and have not enough nurse staff in our ward and we
HAVE TO just pay attention to critical elements of our duties, not all aspects....you see, there are some colleagues who come to hospital for shifts from this morning at 8:00 until tomorrow at 8:00 am or even 2:00 pm. I definitely do not have the same energy tomorrow at 10 am or, for example, at four o'clock in the morning, I'm less responsive to clients, and I do not have much contact with the patient, and neither more contact with other colleagues. In fact, social responsibility of nurses is very dependent on situations and circumstances. The nurse is a human and has a physicist and a body, and is not a machine.... In my opinion, if nursing standards are followed and adequately addressed, nurses will be more socially responsible".

For "Multi-dimensional and comprehensive approach "theme, the new subcategories such as "inter-professional communication", "multi-dimensionality", "considering the organization (hospital) benefits" and "having a motherlike behavior" were also added.

Inter-professional communication: For many participants, a responsible social nurse does not merely focus just on the patients and cares for them, but also is in contact and communicate with all the professionals involved in the hospital, such as other nursing staff, doctors and even patient companions. Here's a sample of participants' talk:

"Social responsibility is the respect for the rights of everyone in the society, not just patients, like your colleagues, your boss or head nurse, doctors, patient companions and actually everyone you face in the society".

Multi-dimensionality: "If nurses during their work and doing their duties, consider not just patients but also other aspects which most of the time, are overlooked, like patients' mental and psychological state, their economic problems, and even the environmental attention and the equipment which is available in the hospitals and use them more effectively, we can say those nurses are definitely a better nurse, and we can say they consider all aspects of social responsibility".

Considering the organization (hospital) benefits: Some participants believed that a nurse should also be committed to the hospital where he or she works, and should bring some advantages for his/her hospital or at least not harm it.

Having a mother-like behavior: When we asked the participants how a responsible social nurse likes, many of them answered: a mother. Because a mother pays attention to all matters (children, future of children, husband, household economics, family problems, etc.). In their view, if a nurse wants to be a socially responsible one, he/she should pay special attention to all issues.

"If a nurse has the view that is like a mother for patients, she certainly will be more responsible for the patients. And a mother always thinks of everything, like the household appliances, the father and the kids, and everything in common".

For the theme of "Spirituality-based", subcategories like "Attention to conscience" and "self-sacrifice" were also added.

Attention to conscience: Many interviewees expressed a 
strong connection between conscientiousness and social responsibility. It is clear that the conscience of humans always commands to good and right things, and when it is said that a person is suffered from conscience punishment, it means that he has committed an act contrary to things that are known as good and legal ones in public.

"In my opinion, anyone who is more conscientious is more responsible, too. This person is worried about one thing conscientiously, in fact, he is always worried about a certain measure, or an answer that he should give himself, to his conscience and to his God...".

Self-sacrifice: Examples of some speeches that bring the researchers to this subcategory are given below.

"Responsibility for nursing means that as soon as you enter the university and the nursing school, you accept that your job is very different from many other jobs..., yes, most of the time, you have to sacrifice your needs and your life for your patients and caring them. Because, apart from the responsibilities of the home and personal life, you are responsible for the LIFE of a sick person".

Results of the final analytical phase: In this phase, with the combination of theoretical and fieldwork phase (Table $3)$, the final definition of the concept was presented:

"Social responsibility is a "learner-based" attribute that is "comprehensive, spirituality based, and relative," meaning that people with higher social responsibility find themselves in relation with the "environmental and human factor" of the society in which they live and work, and they do this through benevolent and voluntary activities that are not expected to receive rewards in return for doing so. In many cases, they try to do the best and most possible work for the patient or client, depending on the situation and circumstances, and somehow sacrifice and dedicate themselves to the patient. The first step in acquiring social responsibility is that the person must be accountable, and then this attribute in later stages and over time in the presence of factors such as learning it in the family and school, and the society, and undergoes an evolutionary process. And ultimately, it increases job satisfaction as much as possible, creates more loyal forces in the organization, develops social justice and increases the quality of health care".

\section{Discussion}

Nurses are the largest group of health professionals, providing and supplying health care in large metropolitan towns and cities all over the world, from primary care clinics to intensive care units. So one of the most important elements in presenting current and future issues of being an effective and good nurse is obtaining social responsibility skill. Considering the concept of social responsibility in the nursing profession needs that our discipline concentrates on envisioning a worldwide approach to the meaning of social responsibility for societies and communities. Specific approaches and strategies to social responsibility, its definition, application to nursing, and application to nursing programs must be presented in clinical and academic settings. This article focused on the clarification of the concept of social responsibility in nursing and its attributes.

Table 3. Attributes derived from the review of the literature and fieldwork (Analytical Phase)

Theoretical Phase
Multi-dimensional and comprehensive
Attention to the community environ-
mental factor
2- Attention to the human factor of the
community
Spirituality-based with two subcatego-
ries: 1- voluntary actions. 2- benevolent
actions
actions

Leaner-based

An evolutionary process

Fieldwork Phase

Multi-dimensional and comprehensive approach with 6 subcategories: 1- Attention to the community environmental factor. 2-Attention to the human factor of the community. 3- Inter-professional communication. 4-Multidimensionality. 5Considering the organization (hospital) benefits. 6- having a mother-like behavior Spirituality-based with four subcategories: 1- voluntary actions. 2- Benevolent actions. 3- Attention to conscience. 4- Selfsacrifice.

Learner-based

An evolutionary process

Relativity with three subcategories: 1Attention to the conditions. 2- Do the best in any situation. 3- Maximum assistance in any circumstances.

Analytical Phase

Multi-dimensional and comprehensive approach in nursing social responsibility means: paying attention to both the community environmental factor and to the human factor of the community and also, having interprofessional communication and being multidimensional (being holistic). A socially responsible nurse should consider the organization (hospital) benefits, too and having a mother-like behavior.

Spirituality-based in nursing social responsibility means doing voluntary and benevolent actions. In addition, a nurse with social responsibility skill always pays attention to his/her conscience and in making decisions refers to it and most of the time he/she has to sacrifice his/her own life and needs in order to save a life.

social responsibility is a process that one must learn from the earliest years of childhood to deal responsibly with the many tasks he faces in life

the achievement of social responsibility as a timeconsuming process, and that, obviously, no organization overnight is mature enough to deal with social problems and problems in social accountability, and this is a process that is time-consuming, requiring the development of new attitudes and perceptions, tasks, policies and programs Relativity in nursing social responsibility means basis on the situations, conditions and problems which a nurse encounters (such as the difficulty of work, the numerous physical and psychological complications of nursing personnel, high job shifts, and sometimes in succession, lack of nursing staff, high numbers of patients, lack of adequate state support from the nurses' community) he/she cannot fully support other aspects of social responsibility or does not do something beyond the main responsibilities for the clients either. 
In the current study in analyzing, five attributes were extracted as follows: comprehensive, spirituality-based, learner-based, an evolutionary process and being relative.

One of the themes that didn't mentioned in literature was "relativity". It seems that the relativity of social responsibility is different in different cultures, societies, and depends on perceptions of people, as well as the conditions and problems in hospitals in Iran (these conditions might not exist in other countries). The reason for which the nurses regard social responsibility as relative might be the conditions and problems they encounter in Iran such as the difficulty of work, the numerous physical and psychological complications of nursing personnel, high job shifts, and sometimes in succession, lack of nursing staff, high numbers of patients, lack of adequate state support from the nurses' community, etc. Therefore, when a nurse is not supported and does not receive enough attention for his or her needs, he/she cannot fully support others or does something beyond the main responsibilities for the clients either. In fact, most of the nurses in Iran just perform their routine cares and duties based on the physician's orders and cannot be expected to fulfill other aspects of care such as paying attention to the benefits of the hospitals, following patient's condition at home and taking into account the environment etc... (all of them are identified as social responsibility). In fact, Iranian nurses try to do their best in any situation due to their religious beliefs and because they think that they are responsible before God in many situations, but when the situations of the hospital and profession are not suitable, their performance decreases and they only carry out their expected responsibilities. Therefore, it seems that conducting the interviews can largely help to clarify social responsibility definition in nursing and ultimately provide much better quality of nursing care. Some of these strategies include more clarifying the concept of social responsibility in nursing, conducting further research on the examination of barriers to care in the economic and social fields, familiarity of the public with nursing and public media care, taking into account salaries and benefits for nurses, holding more educational classes related to social responsibility etc.

Other themes have also come to the fore in the definition of social responsibility (such as comprehensive, spirituality-based, learner-based, and an evolutionary process in other texts) and they were mentioned and delineated at the theoretical phase completely.

\section{Limitations}

One limitation of this study was highly poor access to the full-text articles. Another limitation was the language barrier, so we used the literature in English or Persian languages. In addition, nursing social responsibility is a context-based concept that requires to be examined from the perspectives of different contexts and cultures in order to provide a comprehensive definition.

\section{Conclusion}

The findings of this study could be used to clarify the concept of social responsibility in the health and treatment system. Furthermore, an instrument for measuring the social responsibility of nurses can also be developed in terms of the dimensions identified in this study. Finally, studying and considering the nursing experts' perspectives and also the findings of previously conducted studies on the same topic could be used to take steps to remove barriers and prevent the provision of nursing quality care.

The last but not the least point to mention is that clarifying the concept of social responsibility in nurses and highlighting it in nursing will definitely lead to satisfaction in patients and clients, professional development and reduction of health care costs. Also, by identifying facilitators, inhibitors and social responsibility concepts, nursing managers and nursing educators will be able to design and implement their management and training activities based on scientific findings and based on the findings that are necessary for the correct learning and implementation.

\section{Acknowledgments}

This paper was a report of the qualitative part of a mixed method study for nursing $\mathrm{PhD}$ degree and was financially supported by Iran University of Medical Sciences, Tehran, Iran.

\section{Conflict of Interests}

The authors declare that they have no competing interests.

\section{References}

1. Crigger NJ. Nursing ethics in an era of globalization. ANS Adv Nurs Sci. 2008;24(2):1-18.

2. Kelley MA, Connor A, Kun KE, Salmon ME. Social responsibility: Conceptualization and embodiment in a school of nursing. Int J Nurs Educ Scholarsh. 2008;5(1).

3. Parsapor A, Bagheri A, Larijani B. Patients' rights in Iran. J Med Ethics. 2009;2(4):39-47.

4. Babamahmodi F, Meftahi M, Khademlo M, Hesamzadeh A. Evaluation of patient rights, patient perspective. J Med Ethics. 2011;4(4):3744.

5. Karimimoneghi H, Khatontaheri N, Behnamvashani H, Vagheei S, Yavari M. The Effect of Communication Skills Training on the Quality of Nursing Care of Patients. A chapter on evidence-based care. 2012;2(4):38-46.

6. Sincox K. The conscience of the health care system, Michigan Nurse. [Internet]. [Cited August 2005]. Available from: www.minurses.org.

7. Barati Marani A, Sajadi H, Keivan Ara M. Social responsibility in hospitals of Isfahan city. Payavard. 2011;5(1):10-23.

8. Tyer-Viola L, Nicholas PK, Corless IB, Barry DM, Hoyt P, Fitzpatrick JJ, et al. Social responsibility of nursing: a global perspective. Policy Polit Nurs Pract. 2009;10(2):110-8.

9. Shaner-McRae H, McRae G, Jas V. Environmentally safe health care agencies: nursing's responsibility, Nightingale's Legacy. Online J Issues Nurs. 2007;12(2):1.

10. Spitzer R. Social responsibility, the DNA of leadership. Nurse Leader. 2010;8(1):6.

11. Rafatian AH. Accepting responsibility. Tehran: Ashore Gate Pub; 2006:45-65.

12. Talebi A, Khoshbin Y. Youth social responsibility. Soc Sci Q. 2010;59:207-240.

13. Beikzad J, Hoseinpour A, Hejazi Bavil M. A Survey on the Relationship between responsibility and job satisfaction of nurses working in Teaching Hospitals Affiliated with Tabriz University of Medical Sciences. J Hosp. 2014;13(1):53-60.

14. Schwartz-Barcott D, Kim HS. A hybrid model for concept development. In: Chinn PL, ed. Nursing Research Methodology: Issues and Implementation. Rockville: Aspen; 1986. pp. 91-101.

15. Seomun GA, Chang SO, Lee PS, Lee SJ, Shin HJ. Concept analysis of coping with arthritic pain by South Korean older adults: development of a hybrid model. Nurs Health Sci. 2006;8(1):10-9. 
16. Fleming, M. What is safety culture? Rail way safety ever green House, Available at: www.google.com \rwfl. 2002.

17. Stainer A, Stainer L. Productivity, quality and ethics: A European viewpoint. Eur Business Rev. 1995;95(6):3-11.

18. Panwar R, Han X, Hansen E. A demographic examination of societal views regarding corporate social responsibility in the US forest products industry. For Policy Econ. 2010;12(2):121-28.

19. Salehi Amiri SR, Hajiyani E, Omidvar A, Omidiyani SH, Khalili M, Sasani H, et al. Organization's social responsibility. Tehran: Research Institue of Strategic Researches. 2008:9-89.

20. Taghizadeh H, Soltani GHR. Impact on business ethics and social responsibility of firms. J Morality Technol. 2010;5(3 \& 4):94-104.

21. Wyatt DA. Nurses' responsibility for the future of nursing. Aron J. 2012;95(5):565-6.

22. Vogt L, Sumaya L. The five factor model of personality and individualism/collectivism in South Africa: an exploratory study, PINS. 2009;37:39-54

23. Yazdan panah L, Hekmat F. Investigating the Factors Affecting the Social Responsibility of Youth (Study of Students of Shahid Bahonar University of Kerman. Iran Soc Stud. 2014;8(2):127-150.

24. Ahmadi K, Alvani SM, Memarzade Tehran Gh. Developing the social organizational responsiveness and providing a model for its conceptual extension in Iranian organizations. Indust Manag J Islam Azad Uni. 2011;6(18):97-116.

25. Walker L, Avant K. Strategies for Theory Construction in Nursing. 4th ed. 2005: Appleton \& Lange, Norwalk. 50-160. 